IZA DP No. 1235

In-School Work Experience, Parental Alowances, and Wages

Christian Dustmann J ohn Micklewright Arthur van Soest

August 2004 


\title{
In-School Work Experience, Parental Allowances, and Wages
}

\author{
Christian Dustmann \\ University College London, CEPR, \\ IFS London and IZA Bonn \\ John Micklewright \\ University of Southampton \\ and IZA Bonn \\ Arthur van Soest \\ RAND, Tilburg University \\ and IZA Bonn
}

\section{Discussion Paper No. 1235 \\ August 2004}

IZA

P.O. Box 7240

53072 Bonn

Germany

Phone: +49-228-3894-0

Fax: +49-228-3894-180

Email: iza@iza.org

Any opinions expressed here are those of the author(s) and not those of the institute. Research disseminated by IZA may include views on policy, but the institute itself takes no institutional policy positions.

The Institute for the Study of Labor (IZA) in Bonn is a local and virtual international research center and a place of communication between science, politics and business. IZA is an independent nonprofit company supported by Deutsche Post World Net. The center is associated with the University of Bonn and offers a stimulating research environment through its research networks, research support, and visitors and doctoral programs. IZA engages in (i) original and internationally competitive research in all fields of labor economics, (ii) development of policy concepts, and (iii) dissemination of research results and concepts to the interested public.

IZA Discussion Papers often represent preliminary work and are circulated to encourage discussion. Citation of such a paper should account for its provisional character. A revised version may be available directly from the author. 
IZA Discussion Paper No. 1235

August 2004

\section{ABSTRACT \\ In-School Work Experience, Parental Allowances, and Wages*}

In many industrialised countries, teenagers have a significant spending power, and they are important customers for specialised industries. The income of teenagers still in full time education comes from two major sources: parental pocket money, and earnings from part time jobs. Little is known about the way these sources interact, and how they depend on parental, school and family characteristics. In this paper, we analyse labour supply of 16 year old British teenagers together with the cash transfers made to them by their parents. We develop a theoretical model, which serves as a basis for the empirical specification in which labour supply and transfers are jointly determined. We estimate this model using unique data on labour supply of teenagers, the wages they receive, and transfers made to them by their parents. We show how these two processes depend on each other, and how transfers and labour supply react to changes in wages.

JEL Classification: J22, C7, C35

Keywords: intra-household transfers, teenager labour supply

Corresponding author:

Christian Dustmann

Department of Economics

University College London

Gower Street

London WC1E 6BT

United Kingdom

Email: c.dustmann@ucl.ac.uk

\footnotetext{
* We are grateful to the Leverhulme Trust for financial support for this research, which has also benefited from support to the IFS as a Designated Research Centre of the ESRC. We thank Murali Agastya, Richard Blundell, Ian Preston and Frank Windmeijer for useful comments.
} 


\section{Introduction}

In developing countries, wage income of children often contributes importantly to the family's subsistence income. Children frequently work full time (and often in the agricultural sector, see Bhalotra and Heady 2000), with lasting negative consequences for their own well being. ${ }^{1}$ One well documented consequence of early labour market commitment of children is a reduction in their educational achievements. ${ }^{2}$

In contrast, in Western countries labour market participation of children is not in general borne out of subsistence needs of the family. A major purpose of job earnings of teenagers is to finance non-subsistence consumption goods. Teenagers have become important consumers of items like clothing and specific leisure articles, and they are targeted by specialist industries. Part time work during full time education may however have effects on the well-being of the child, over and above the direct purpose of obtaining additional resources. One concern may be the impact of part time work on educational achievement. Dustmann, Micklewright, Rajah and Smith (1997) illustrate that part time work during full time education may have detrimental effects on examination results. Ehrenberg and Sherman (1983) investigate the effect of part-time work during full-time education on academic performance and subsequent enrollment, and find a negative effect on enrollment and probabilities of graduating in time. On the other side, working part time during full time education may provide teenagers with a taste of what the real labour market is like, and allow them to make more informed career choices. Ruhm (1997) and Light (2001) find a positive correlation between job

\footnotetext{
${ }^{1}$ For research on the labour supply of children, its effects on the process of human capital formation, and its relation to family wealth and family background, see the review of Basu (1999).

${ }^{2}$ See e.g. Rosenzweig and Evenson (1977).
} 
commitment at high school and future economic outcomes, while Hotz, Xu, Tienda and Ahituv (2002) find that positive effects diminish and are not statistically significant when controlling for dynamic selection.

Either way, parents may want to have some influence on their children's part time work. One way to do that is to regulate the second source of income which, besides odd jobs, funds teenagers personal consumption: parental cash transfers. On the one hand, children may reduce their willingness to work part time when transfers are increased. On the other hand, a reduction in parental allowances may induce teenagers to take up some part time work, or to increase hours in an existing job. There are a number of studies that analyse the transfer of parental resources to adult children (see, e.g., Altonji, Hajashi and Kotlikoff 1997, Dunn and Philips 1997, and Hochguertel and Ohlsen 2000). Sauer (2002) develops a dynamic programming model to analyse and estimate the effects of parental cash transfers, received during school school studies, on educational borrowing and in-school work decisions, and on post-graduation lifetime earnings.

However, there is hardly any work that investigates the relationship between parental transfers and part-time work for teenagers still in full time education. The only study we are aware of is Wulff-Pabilonia (2001) who studies data from the NLSY 1997. She finds a negative and statistically significant relationship between parental allowances and the probability of employment for 14-15 and 16 year old teenagers.

The relationship between part time work of school children and parental allowances may go either way, however. Parental pocket money may not only influence the child's part time work, but the child's decision to take up a part time job may also affect transfers to the child from the parent. As a consequence, any negative correlation 
between child's labour supply and transfers may be either due to children reacting to changes in parental allowances, or parents reacting to their child's labour supply decisions, or both. Analysing part time work of teenagers, or parental transfers, in isolation may therefore result in misleading conclusions.

One objective of this paper is to provide a framework for analysing parental cash transfers, and labour supply of children within a model that recognises the interactive nature between the two processes. To our knowledge, no work exists on how cash transfers and child's labour supply are determined within the family. There are however some related models in the literature on the transmission of goods within the family. Becker $(1974,1981,1993)$ was the first to analyse intra family transfers between an altruistic parent (or husband), and a selfish child (or wife). Others have developed and explored extensions of this model, in particular to consider the case where the beneficiary can determine his or her own income via labour supply (see, e.g., Bergstrom 1989 and Juerges 2000). We develop a theoretical model that is motivated by this work. In our model, the beneficiary (a selfish child in our case) chooses his or her labour supply, taking transfers of the parents as given. Altruistic parents choose the optimal transfers, taking the child's labour supply decision into account. The theoretical model leads to an econometric model explaining both transfers and labour supply, taking into account interdependencies between the two as well as a wide range of other factors, such as family background and parental income.

The second contribution of our paper is to estimate the effect parental transfers have on child's labour supply, and whether the decision of the child to work reduces parental transfers. In addition, we analyse how both labour supply and transfer payments react to changes in the wage rate. Furthermore, we investigate how family background 
variables affect these two decisions.

Our data, which stems from the British national Child Development Survey (NCDS), is unusually rich in information for the purpose of our study. It does not only include intra-household transfers and information on children's labour supply as well as weekly wages, but also a large set of family background variables and characteristics of the children, such as the parents' education levels and labour force status and a uniform test measure of the child's reading and math ability. This enables us to estimate a structural empirical model in which transfers and labour supply are jointly determined.

The structure of the paper is as follows. In the next section, some evidence of children's pocket money allowances and labour supply is presented. A theoretical framework that helps us to understand the interactive nature between parental transfers and children's labour supply is developed in Section 3. In section 4, we discuss the data and variables, and present the empirical model. Results of the analysis are presented in section 5. Section 6 concludes.

\section{Part-Time work of Children and Parental Al-}

\section{lowances}

Labour force participation of teenagers still in full time education is substantial. In the US, the sizeable employment rates among 14-15 year olds in school have long been known, with rates of about 25 percent at the end of the 1970 s, rising to 50 percent for 17 year olds (Michael and Tuma 1984). Wulff-Pabilonia (2001) reports, again for the US, that in 1996, 56 percent of 16-year olds hold a job. In Britain, rates of between 30 
percent and 50 percent for 16-17 year old teenagers in full-time education can be seen for the early 1990s (the level varying with the definition of employment and source of data used) with a marked rise in participation over the previous decades (Sly 1993, Micklewright, Rajah and Smith 1994).

The data we use for our study are drawn from the British National Child Development Study (NCDS), which follows all children born in one week in March 1958. Information has been collected on these individuals and their families at various points in their lives - at birth and at ages $7,11,16,23,33$, and 42 . We draw mainly on the data collected in Spring 1974, known as "NCDS3", when the individuals were aged 16 and in their last year of compulsory schooling. ${ }^{3}$

The NCDS3 data provide a rich source of information on the subject under investigation. Data were collected separately from four sources - from the children themselves, from parents, from schools, and from family doctors. Interviews with the children include questions on labour supply, earnings, and pocket money. Information on a range of household characteristics, including income, were collected from parents. The schools conducted standardised tests of the children's ability that were added to the survey data base. Moreover, the survey provides a reasonably large sample - our analysis is of 5,035 children. Nevertheless, attrition and missing data mean that this sample is considerably smaller than it might have been. We lose a lot of information due to missing questionnaires which cover some of the variables we use, or from incomplete information necessary to construct some of the regressors (like family income).

The survey provides detailed information on weekly parental cash transfers, and

\footnotetext{
${ }^{3}$ The NCDS children were in the first birth cohort required to stay at school until 16.
} 
on labour supply of children. It also gives some details on how teenagers spend their money. In addition, we observe teenagers' weekly earnings in banded form, allowing us to construct hourly wages and to estimate their responsiveness to wage changes. In what follows, we report all wage, transfers, and income information in 2003 prices. Tables 1 and 2 provide information on the distributions of the two variables that we seek to explain, weekly hours of work and transfers, separately for girls and for boys. The first column reports the mean of hours worked, evaluated at the midpoints of the banded hours information. Teenage boys work slightly more hours on average than teenage girls - 4.09, as compared to 3.61. There is a stark difference in labour supply for those who receive transfer payments, with those who receive transfers working about half as many hours than those who do not receive any payments.

The next columns trace the distribution of hours worked, for all individuals, and those who do, and do not receive transfer payments. More than one in two teenagers in our sample report a regular term-time job. This percentage is considerably higher for those who do not receive any transfers, where 85 percent participate, with almost identical percentages for boys and girls. The distribution of working hours is shifted to the right for those who do not receive transfers, and boys tend to be in the upper range of labour supply, relative to girls.

The first column in table 2 reports mean transfers for all individuals, and for those who do and do not work. Girls receive on average slightly higher transfers than boys - which could be related ton their lower labour supply. There is a sizeable difference between transfer payments to individuals who do, and who do not work - for boys, labour market participants receive on average 6.81 pounds weekly transfers, while nonparticipants receive 9.15 pounds. The numbers for girls are 7.21 and 9.47 pounds 
Table 1: Distribution of Weekly Hours Worked

\begin{tabular}{l|c||ccccccc|c}
\hline \hline Hours & Mean & None & $<3$ & $3-6$ & $6-9$ & $9-12$ & $12-15$ & $15+$ & Total \\
\hline Girls & & & & & & & & & \\
All & 3.61 & 49.52 & 2.94 & 16.72 & 20.53 & 5.16 & 2.46 & 2.66 & 100 \\
Transfers $=0$ & 6.33 & 15.53 & 4.97 & 23.60 & 36.02 & 8.70 & 6.21 & 4.97 & 100 \\
Transfers $>0$ & 3.42 & 51.85 & 2.80 & 16.25 & 19.47 & 4.92 & 2.21 & 2.50 & 100 \\
\hline Boys & & & & & & & & & \\
All & 4.09 & 48.30 & 6.47 & 13.09 & 13.69 & 6.92 & 4.84 & 6.69 & 100 \\
Transfers $=0$ & 7.95 & 15.23 & 6.17 & 16.46 & 17.70 & 15.23 & 12.76 & 16.46 & 100 \\
Transfers $>0$ & 3.70 & 51.65 & 6.50 & 12.74 & 13.29 & 6.08 & 4.04 & 5.71 & 100 \\
\hline \hline Using bracket midpoints
\end{tabular}

respectively. The following columns trace the distribution of transfer payments for the three groups. The great majority of teenagers receive some cash transfers from their parents, with the percentage of boys receiving no payments being slightly higher than that of girls. Also, among those who work, the percentage of boys receiving no transfers is higher than the percentage of girls. The amounts of transfers vary considerably, but the overall distributions are roughly similar for boys and girls. About 1 in 11 receive positive amounts of less than 3.50 pounds per week, while 1 in 8 receives 14 pounds or more.

Table 2: Distribution of Transfer Payments

\begin{tabular}{|c|c|c|c|c|c|c|c|c|c|c|}
\hline Transfers & Mean* & None & {$[0,3.50)$} & {$[3.50,5.25)$} & {$[5.25,7)$} & {$[7,10.50)$} & {$[10.50,14)$} & {$[14,21)$} & $21+$ & Total \\
\hline \multicolumn{11}{|l|}{ Girls } \\
\hline$\overline{\text { All }}$ & 8.33 & 6.43 & 8.99 & 22.42 & 12.03 & 24.90 & 12.07 & 7.99 & 5.16 & 100 \\
\hline Hours $=0$ & 9.47 & 2.02 & 6.63 & 20.53 & 12.37 & 26.60 & 15.04 & 10.59 & 6.22 & 100 \\
\hline Hours $>0$ & 7.21 & 10.75 & 11.30 & 24.27 & 11.70 & 23.24 & 9.17 & 5.45 & 4.11 & 100 \\
\hline \multicolumn{11}{|l|}{ Boys } \\
\hline$\overline{\text { All }}$ & 7.94 & 9.30 & 8.76 & 23.96 & 12.02 & 21.97 & 11.02 & 8.19 & 4.78 & 100.00 \\
\hline Hours $=0$ & 9.15 & 2.93 & 6.74 & 22.50 & 12.28 & 25.83 & 13.95 & 9.67 & 6.10 & 100.00 \\
\hline Hours $>0$ & 6.81 & 15.25 & 10.66 & 25.31 & 11.77 & 18.36 & 8.29 & 6.81 & 3.55 & 100.00 \\
\hline
\end{tabular}

Transfers per week in 2003 British Pounds.

$*$ : Using bracket midpoints. 
The numbers in tables 1 and 2 suggest that transfer payments and hours of work are two processes which interact strongly, with those receiving transfers having lower participation probabilities, and those working receiving less transfers. However, these numbers are unconditional, and allow no conclusions to be drawn about the possible causality, as well as the way transfers and labour supply relate to common observable and unobservable factors. Below we specify and estimate a structural empirical model for these processes. Our model takes also account of responsiveness of both processes to wages teenagers receive. Our empirical specification is based on an estimable theoretical framework for modelling the two processes within a family unit, which we set out in the next section.

\section{A Structural Model of Labour Supply and Trans- fers}

We develop a simple theoretical framework for the relationship between parental allowances towards the child, and the child's part-time work decision. We consider an altruistic parent $(p)$, and a selfish child $(c)$. In our model, the parent sets the optimal level of transfers subject to his or her own budget constraint, taking account of the child's labour supply decision. In turn, the child chooses the optimal supply of labour, conditional on the parent's transfer payments. We first present the model without taking account of non-negativity constraints on transfers or hours. Formally, the child solves the utility maximisation problem: 
Maximize $_{H} U^{c}\left(x^{c}, L\right)$ subject to $x^{c}=w H+T$ and $L=1-H$,

where $x^{c}$ is the child's consumption that has to be paid out of transfers and own earnings, $L$ is leisure time, and $H$ is hours worked. We have normalised the total time available for leisure and work activities to 1 . The child's net hourly wage rate $w$ is assumed not to depend on hours worked; non-proportional earnings taxes are irrelevant for the small amounts of earnings that teenagers typically earn. Finally, $T$ denotes transfers from the parent to the child. We will focus on the case of a Nash equilibrium or a Stackelberg equilibrium with the parent as leader, in both of which the child takes $T$ as given. ${ }^{4}$ The utility function $U^{c}$ is assumed to be quasi-concave and increasing in its first argument.

The parent solves the following problem:

Maximise $_{T} U^{p}\left(x^{p}, u^{c}\right)$ subject to $x^{p}=\delta I-T$ and $u^{c}=U^{c}(w H+T, 1-H)$.

Here $I$ denotes family income excluding the child's earnings and $\delta I$ is the noncommitted part of income that can be allocated for either family consumption of a composite commodity $\left(x^{p}\right)$ or can be given to the child (and then spent on the child's composite consumption commodity $x^{c}$ ) in the form of transfers. The standard model with $\delta=1$ is a special case. In case of a Nash equilibrium (or a Stackelberg equilibrium with the child as leader), the parent takes $H$ as given. In a Stackelberg equilibrium with

\footnotetext{
${ }^{4}$ In a Stackelberg equilibrium with the child as leader, $T$ will be a function of $H$, the form of which depends on the parent's utility function.
} 
the parent as leader, $H$ will become a function of $T$ (depending on the specification of $U^{c}$ and the wage rate $\left.w\right)$.

The Nash equilibrium is determined by the first order conditions for the child and the parent, respectively: ${ }^{5}$

$$
\frac{\partial U^{c}}{\partial L}=w \frac{\partial U^{c}}{\partial x^{c}}
$$

and

$$
\frac{\partial U^{p}}{\partial x^{p}}=\frac{\partial U^{p}}{\partial U^{c}} \frac{\partial U^{c}}{\partial x^{c}}
$$

We shall work with the following generalised Cobb-Douglas specification of the parent's utility function:

$$
U^{p}\left(x^{p}, u^{c}\right)=\left(x^{p}+\gamma_{0}\right)^{\gamma_{1}}\left(u^{c}\right)^{\gamma_{2}}
$$

For the child's preferences we choose a specification suggested by Hausman (1985),

\footnotetext{
${ }^{5}$ For the Stackelberg equilibrium with the parent as leader, the first order conditions are given by (4) and

$$
\frac{\partial U^{p}}{\partial x^{p}}=\frac{\partial U^{p}}{\partial U^{c}}\left(\frac{\partial U^{c}}{\partial x^{c}}+\frac{d L}{d T}\left[\frac{\partial U^{c}}{\partial L}-w \frac{\partial U^{c}}{\partial x^{c}}\right]\right) .
$$

where $d L / d T$ is the slope of the child's reaction curve. Since (4) implies that the term in square brackets is zero, the Stackelberg equilibrium with the parent as leader will give the same solution as the Nash equilibrium. Similarly, it can be shown that the "equilibrium" in which the parent acts as an altruistic dictator and determines both $H$ and $T$ gives the same solution. The reason is that $H$ enters $U^{p}$ only through $U^{c}$. Only the Stackelberg equilibrium with the child as leader would give a different solution.
} 
which gives rise to an easily interpretable and linear labour supply function: ${ }^{6}$

$$
\left.U^{c}\left(x^{c}, L\right)=\alpha_{1}-\alpha_{2}(1-L)\right) \exp \frac{\alpha_{2}\left((1-L)-\alpha_{0}-\alpha_{2} x^{c}\right)}{\alpha_{1}-\alpha_{2}(1-L)}
$$

with $\alpha_{1}>0$ and $\alpha_{2}<0$. These inequalities guarantee that the utility function is quasi-concave and increasing in its first argument. It can be decreasing in leisure (particularly for high values of leisure). The labour supply function is given by:

$$
H=\alpha_{0}+\alpha_{1} w+\alpha_{2} T
$$

This specification has been used quite often in the labour supply literature (see the overview in Blundell and MaCurdy, 1999).

Combining (8) with parental preferences in (6) gives the following first order condition for transfers:

$$
T=\pi_{0}+\pi_{1} I+\pi_{2} H
$$

where $\pi_{0}=\gamma_{0}-\gamma_{1} \alpha_{1} /\left(\gamma_{2} \alpha_{2}^{2}\right), \pi_{1}=\delta$, and $\pi_{2}=\gamma_{1} /\left(\gamma_{2} \alpha_{2}\right)$.

Accounting for non-negativity constraints on $H$ and $T$ results in the following system:

$$
H=\max \left(0, \alpha_{0}+\alpha_{1} w+\alpha_{2} T\right),
$$

${ }^{6}$ An alternative specification that leads to closed form expressions for the optimal hours and transfers is a generalized Cobb-Douglas similar to the utility function for the parents. We estimated the model using that specification but it gave a lower goodness of fit than the Hausman specification. Results were similar to those we report below. 


$$
T=\max \left(0, \pi_{0}+\pi_{1} I+\pi_{2} H\right)
$$

This system will have exactly one solution if $\alpha_{2} \pi_{2}<1$, i.e., if $(0<) \gamma_{1}<\gamma_{2}$.

Since $\alpha_{2}<0$, equation (10) says that the child will supply labour only if transfers are below a certain threshold. Above that threshold, labour supply equals zero. The critical level depends on the child's preferences for consumption and leisure time and on the wage rate. The higher the child's preference for consumption, relative to leisure, the higher the level of transfers necessary to induce the child not to work. Transfer payments induce a negative income effect and reduce the participation propensity.

Since $\pi_{2}<0$, equation (11) says that transfers are positive as long as the child's labour supply falls below a certain threshold, which depends positively on parental income, and on the parent's degree of altruism. Notice that in this model, parental income affects the child's labour supply only through transfer payments.

\section{The Empirical Model}

To identify the parent's utility function, a normalisation has to be imposed. Without loss of generality, we assume $\gamma_{1}+\gamma_{2}=1$. With this normalisation, there is a one-to-one correspondence between the parameters in (10) and (11) and the structural parameters in the parent's and child's utility functions. Estimates of the parameters in (10) and (11) can immediately be transformed into estimates of the structural parameters.

We will separately estimate models for boys and girls. To allow for further observed and unobserved heterogeneity in preferences of parents and children, the parameters $\gamma_{0}\left(\right.$ or $\left.\pi_{0}\right)$ in the parent's utility function and $\alpha_{0}$ in the child's utility function will be 
specified as linear functions of observed background characteristics (denoted by $X_{T}$ and $X_{H}$ respectively) and an error term $\left(\epsilon_{T}\right.$ and $\epsilon_{H}$ respectively). ${ }^{7}$ The other preference parameters are assumed to be the same for all observations in the sample. This gives the following empirical model (with separate parameters for boys and girls):

$$
\begin{aligned}
& H=\max \left(0, X_{H} \alpha+\alpha_{1} w+\alpha_{2} T+\epsilon_{H}\right) \\
& T=\max \left(0, X_{T} \pi+\pi_{1} I+\pi_{2} H+\epsilon_{T}\right),
\end{aligned}
$$

where $\alpha$ and $\pi$ are vectors of parameters. The error terms are assumed to have normal distributions with mean zero and unknown variances, independent of the background characteristics, income, and wage rates, and independent of each other.

The model can be estimated by maximum likelihood. If positive, the variables $H$ and $T$ are not observed exactly, but categorical information is available. Thus we always observe an interval containing $H$ and an interval containing $T$. These intervals can be used to construct the likelihood contributions, which are bivariate normal probabilities for $\epsilon_{T}$ and $\epsilon_{H}$. Suppose, for example, a given observation has $H$ between 9 and 12 and $T$ between 7.5 and 14. Since both $H$ and $T$ are positive, (12) and (13) for this observation simplify to

$$
\begin{aligned}
& H=X_{H} \alpha+\alpha_{1} w+\alpha_{2} T+\epsilon_{H}, \\
& T=X_{T} \pi+\pi_{1} I+\pi_{2} H+\epsilon_{T} .
\end{aligned}
$$

\footnotetext{
${ }^{7}$ The index indicating the observation is suppressed.
} 
Solving for $H$ and $T$ gives

$$
\begin{aligned}
& H=\frac{X_{T} \alpha+\alpha_{1} w+\alpha_{2}\left(X_{T}+\pi_{1} I+\epsilon_{T}\right)+\epsilon_{H}}{\left(1-\alpha_{2} \pi_{2}\right)}, \\
& T=\frac{X_{T} \pi+\pi_{1} I+\pi_{2}\left(X_{H} \alpha+\alpha_{1} w+\epsilon_{H}\right)+\epsilon_{T}}{1-\alpha_{2} \pi_{2}} .
\end{aligned}
$$

This implies that, for given values of parameters and regressors (including $I$ and $w)$, the probability that $H$ is between 9 and 12 and that $T$ is between 7.5 and 14 , is the bivariate probability that two linear combinations of $\epsilon_{H}$ and $\epsilon_{T}$ are in some rectangle. Thus the likelihood contribution of this observation is a bivariate normal probability which is straightforward to compute. For other types of observations, likelihood contributions can be derived in a similar $(H>0$ and $T>0)$ or easier $(H=0$ or $T=0)$ way. ${ }^{8}$

So far, we have not specified the type of transfers parents make to their children. Transfers may be in kind or in cash, and in our data we observe only those in cash. The data may therefore lead us to overestimate the size of transfers for those who do have to buy goods that are provided to others as an in-kind transfer. The data provides us with qualitative information on whether or not the cash transfer the child receives is meant to cover expenses like travel, clothes, or meals, and we use this information in the empirical model. We multiply transfer amounts that are reported to include amounts to be spent on travel, clothes, etc., by a correction factor, to transform them into

\footnotetext{
${ }^{8}$ The model is well-defined (or coherent, see Gourieroux, Laffont and Monfort, 1980) if $\alpha_{2} \pi_{2}<1$.
} All our estimates satisfy this inequality without imposing it, implying that coherency is not a concern here (cf. van Soest, Kooreman and Kapteyn, 1993). 
corresponding transfer amounts that do not include these expenditures. The correction factor $\tau$ is assumed to be the same for all boys and all girls in the sample. It will be estimated jointly with the other parameters; we expect it to be smaller than one. ${ }^{9}$

The model is identified without exclusion restrictions on $X_{H}$ or $X_{T}$, since $w$ enters the equation for $H$ but not the equation for $T$, while family income $I$ enters the equation for $T$ but not the equation for $H$. In addition, the error terms $\epsilon_{T}$ and $\epsilon_{H}$ are independent, and the censoring provides additional structure.

\section{Description of Variables}

The variables in $X_{T}$ and $X_{H}$ are described in table 3. In addition to these variables, we condition on regional dummy variables in all estimations below.

In table 3, we report separately for girls and boys mean and standard deviation of the set of variables we use.

Skill level and labour market status of the parents (indicator variables on whether the father works, is self employed, works on a farm, and whether the mother works), as well as educational background of father and mother (their school leaving age) are likely to be related, on the one hand, to preferences and opportunities of the child regarding part time work. On the other hand, these variables may be related to parental judgements about the amount of transfers which should be allocated to children. For instance, parental education may be related to the child's preferences for academic activities, thus reducing the propensity to work during school attendance. At

\footnotetext{
${ }^{9}$ In the likelihood, this can be incorporated by multiplying the threshold values with $1 / \tau$ for observations where expenditures on travel, clothes, etc. are included.
} 
Table 3: Descriptive Statistics

\begin{tabular}{l|rrrr}
\hline \hline & \multicolumn{2}{|c}{ Girls } & \multicolumn{2}{c}{ Boys } \\
\hline Variable & Mean & StdD & Mean & StdD \\
Father Works & 88.91 & 31.39 & 89.60 & 30.4 \\
Father Self Employed & 4.13 & 19.90 & 3.92 & 19.5 \\
Father Farmer & 2.38 & 15.25 & 2.31 & 15.0 \\
Mother Works & 67.71 & 46.76 & 68.6 & 46.3 \\
N. Younger Siblings & 1.24 & 1.29 & 1.27 & 1.28 \\
N. Older Siblings & 1.10 & 1.31 & 1.09 & 1.34 \\
Age Father left school* & 4.02 & 1.75 & 4.02 & 1.80 \\
Age Mother left school & 4.00 & 1.41 & 3.97 & 1.39 \\
Ability Test Score Age 11 & 45.13 & 20.09 & 45.76 & 21.17 \\
Household Income & 350.58 & 134.41 & 346.22 & 124.71 \\
Comprehensive School & 53.25 & 49.90 & 55.6 & 49.6 \\
Grammar School & 14.89 & 35.60 & 11.5 & 31.9 \\
Modern School & 25.25 & 43.45 & 24.8 & 43.2 \\
Technical School & 0.51 & 7.16 & 0.7 & 8.8 \\
Independent School & 4.32 & 20.35 & 4.4 & 20.6 \\
Special Needs School & 1.62 & 12.6 & 2.26 & 14.89 \\
Wage Rate & 2.69 & 1.95 & 3.18 & 2.45 \\
\hline *: Mother' and Father's age when leaving full time education
\end{tabular}

*: Mothers' and Father's age when leaving full time education, minus 12 .

Number of Observations in sample: 5035 .

Household income is total weekly income from earned and unearned sources (including state benefits). This variable is obtained from summing mid-points of banded variables (with 12 categories) for father's earnings, mother's earnings and other income of either parent. See Micklewright (1986) for further details. 
the same time, better educated parents may have different opinions about the amount of pocket money that is beneficial for the child. Also, labour force status of the parents may pick up several effects on child's labour force participation: married women are often working in sectors which more easily provide part time work for children. A self employed father, or a father who works on a farm may reflect a higher demand for the child's work inside the family business.

The type of school the teenager attends may be related to both parental preferences and to the child's "committed leisure", which includes all other demands on the child's time. We include a vector of school type variables (see Dustmann, Rajah and van Soest 2003 for details on the UK school system).

Conditional on household income, transfer payments are likely to be related to other transfer commitments of the parent. Something which captures these commitments is the number of the child's siblings. Our data allows us to distinguish older and younger siblings. We expect the number of siblings to reduce transfers, with the effect of younger siblings being stronger than the effect of older siblings (who are at least 16 years old), since the latter are more likely to be financially independent. Furthermore, older siblings may have experiences with part-time jobs, thus helping the younger teenager to find an appropriate occupation. Younger siblings may impose constraints on the teenager's allocation of time, as they may have to look after them in the parent's absence.

We observe in our data test score results from ability tests the teenager sat at age 11, which are scaled between 0 and $100 .{ }^{10}$ The academic potential of teenagers may

\footnotetext{
${ }^{10}$ The ability index measures general mathematics and English skills at age 11.
} 
affect their labour supply. High ability teenagers are more efficient in solving academic tasks. They spend therefore less time on studying, and are more likely to spare time for employment activities; on the other side, teenagers with a high academic potential may attach more importance to an academic education, and refrain from activities that may endanger their academic success. The effect of ability measures on labour supply is therefore unclear. Ability scores may also affect transfer payments - parents may want to prevent children with weak academic performance from working part time, to avoid endangering their school performance, and therefore compensate them by transfer payments.

The last row of table 3 reports wages of teenagers. We have computed wages from the midpoints of weekly earnings, divided by the midpoints of weekly hours worked. The numbers suggest that wages of female teenagers are slightly lower than wages of male teenagers: 2.7 pounds, as compared to 3.2 pounds.

\section{Results}

We have estimated all models for the pooled sample of male and female teenagers, as well as for boys and girls separately. Maximum likelihood tests strongly reject pooled estimation, and we therefore discuss only models that are separately estimated for the two groups.

Our estimation requires information on hourly wage rates for teenagers. Although our data is quite unique in recording weekly earnings, we do not observe hourly wage rates directly. Instead we observe weekly hours worked and weekly earnings in banded form. We estimate hourly wages from this information. We then use the midpoints 
of the intervals. ${ }^{11}$ As we only observe earnings for individuals who work, we predict hourly wages of nonworkers using a standard Heckman selection model for the log wage rate. $^{12}$

Results for the wage equation of this auxiliary model are presented in Table 6 in the appendix, where we report results for both wage- and selection equation for male and female teenagers. The participation equation is identified by excluding parental education and household income from the wage equation. It is therefore a reduced form equation along the lines of the model we have set up above, with family income affecting participation via transfer payments. The set of instruments is jointly significant at usual significance levels for females (p-value 0.0005) but not quite for males (p-value 0.1189). The correlation between the errors in the two equations is positive for teenage boys and girls, and of roughly similar magnitude, implying that those with higher propensity to participate can earn a higher wage, given the observed characteristics.

\footnotetext{
${ }^{11}$ The banded information on hours worked is described in Table 2; the bands for weekly earnings are $0,(0,7), \ldots,(35,42),(42, \infty)$. Earnings for someone in the first band are set to 3.5 Pounds, etc., up to 45.5 pounds for the last band.

${ }^{12}$ Since we use the actual wage bands for the working teenagers and do not allow for correlation between error terms in the wage equation and the transfers and hours worked equation, the labour supply model is identified without exclusion restrictions, i.e., without the need to include variables in the wage equation that are not in the labour supply equation. Although this is a common approach in much of the labour supply literature, we acknowledge that ideally, the wage equation should be estimated jointly with transfer and labour supply equations. This, however, leads to a much more complicated model and is beyond the scope of the current paper.
} 


\subsection{Labour Supply and Transfers}

We now turn to the labour supply- and transfer equations. In tables 4 and 5 we present our estimation results for teenage boys and girls. Columns 1 and 3 present structural parameter estimates for the labour supply equation and the transfer equation respectively. Columns 2 and 4 present total effects of regressors on labour supply and transfers, which combine both the direct and indirect effects. We report parameter estimates and their standard errors.

When computing the total marginal effects, we consider the case where the nonnegativity constraints are not binding, so that the reduced forms are given by (16) and (17). From these reduced form equations, the (total) marginal effects with respect to changes in exogenous variables $X_{H}, X_{T}$ and $w$ follow immediately. They vary, however, across observations. The estimates in columns 2 and 4 in the tables are averaged over all observations with predicted hours and transfers both larger than zero, for which the nonnegativity constraints are predicted to be non-binding. Furthermore, the error terms $\epsilon_{H}$ and $\epsilon_{T}$ are set to zero. Standard errors are computed by simulating from the estimated asymptotic distribution of the parameter estimates. For each of 500 independent draws of the complete parameter vector, the marginal effects are computed, and the sample standard deviation in these 500 estimates is reported.

Our estimates of the effects of transfers on labour supply, and labour supply on transfers show that, while the effect of transfers on labour supply is precisely estimated, the effect of labour supply on transfers is small, and not statistically significant. Cash transfers induce an income effect, which reduces child's labour supply. The coefficient on the transfers in the labour supply equations for boys and girls are very similar: 
Table 4: Hours Worked and Transfers, Boys

\begin{tabular}{|c|c|c|c|c|c|c|c|c|}
\hline & \multicolumn{2}{|c|}{ Hours } & \multicolumn{2}{|c|}{ Hours, Total } & \multicolumn{2}{|c|}{ Transfers } & \multicolumn{2}{|c|}{ Transfers, Total } \\
\hline & Coef. & Std. Err. & Coef. & Std. Err. & Coef. & Std. Err. & Coef. & Std. Err. \\
\hline Intercept & 1.565 & 1.632 & - & - & 7.188 & 0.729 & 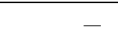 & - \\
\hline Father Works & 0.437 & 0.658 & 0.718 & 0.699 & -0.930 & 0.322 & -0.966 & 0.353 \\
\hline Father Farmer & 5.891 & 1.248 & 6.239 & 1.179 & -0.461 & 0.672 & -0.993 & 0.637 \\
\hline Father Self Employed & 2.626 & 1.073 & 2.684 & 1.169 & 0.068 & 0.468 & -0.141 & 0.477 \\
\hline Mother Works & 1.153 & 0.464 & 1.209 & 0.494 & -0.079 & 0.233 & -0.167 & 0.235 \\
\hline East & 0.675 & 0.824 & 0.388 & 0.797 & 0.991 & 0.431 & 0.950 & 0.445 \\
\hline North West & -0.115 & 0.843 & -0.719 & 0.793 & 1.965 & 0.438 & 1.994 & 0.459 \\
\hline North & -1.632 & 0.925 & -2.338 & 0.916 & 2.188 & 0.469 & 2.357 & 0.502 \\
\hline South West & -0.401 & 1.122 & -0.902 & 1.093 & 1.650 & 0.557 & 1.696 & 0.590 \\
\hline Independent School & -5.877 & 1.217 & -6.330 & 1.282 & 0.872 & 0.613 & 1.432 & 0.667 \\
\hline Special needs school & -3.627 & 1.349 & -3.052 & 1.397 & -1.995 & 0.571 & -1.775 & 0.598 \\
\hline Mode & 0.714 & 0.496 & 0.832 & 0.489 & -0.414 & 0.238 & -0.464 & 0.243 \\
\hline Techr & 3.398 & 2.285 & 3.594 & 2.281 & -0.013 & 1.069 & -0.319 & 1.167 \\
\hline Gram & -0.328 & 0.754 & -0.314 & 0.791 & -0.180 & 0.437 & -0.105 & 0.457 \\
\hline Age Father left school* & -0.253 & 0.141 & -0.219 & 0.148 & -0.122 & 0.071 & -0.111 & 0.074 \\
\hline Age Mother left school* & -0.091 & 0.184 & -0.021 & 0.187 & -0.239 & 0.096 & -0.238 & 0.102 \\
\hline Female & 0.000 & 0.000 & 0.000 & 0.000 & 0.000 & 0.000 & 0.000 & 0.000 \\
\hline N. Older Siblings & 0.020 & 0.158 & 0.041 & 0.170 & -0.066 & 0.070 & -0.062 & 0.076 \\
\hline N. Younger & 0.411 & 0.169 & 0.550 & 0.168 & -0.432 & 0.076 & -0.470 & 0.083 \\
\hline Ability Te & -2.425 & 1.239 & -1.989 & 1.280 & -1.269 & 0.615 & -1.140 & 0.611 \\
\hline Household & 0.000 & 0.000 & -0.144 & 0.065 & 0.476 & 0.095 & 0.480 & 0.101 \\
\hline Adjustment parameter $\tau$ & - & - & - & - & 0.676 & 0.012 & - & - \\
\hline $\mathrm{T}$ in Hours & -0.302 & 0.131 & - & - & - & - & - & - \\
\hline $\mathrm{H}$ in Transfers & - & - & - & - & -0.078 & 0.050 & - & - \\
\hline w in Hours & 0.755 & 0.088 & - & - & - & - & - & - \\
\hline Total Effect Wage rate & - & - & 0.776 & 0.095 & - & - & -0.061 & 0.038 \\
\hline Variance Hours & 9.159 & 0.225 & - & - & - & - & - & - \\
\hline Variance Transfers & - & - & - & - & 4.855 & 0.075 & - & - \\
\hline Log likelihood & & & & & & & & \\
\hline
\end{tabular}


-0.302 and -0.312 respectively. An increase in cash transfers by five pounds leads therefore to a direct reduction in weekly labour supply of about 1.5 hours. This suggests quite a sizeable effect of transfer payments on labour supply, given that mean hours worked per week are 3.9 hours. It implies an income elasticity of teenagers' labour supply of about -0.6 at the mean, which is quite large compared to the income elasticities of adult labour supply that can be found in the literature. This result is in line, however, with the results of Wulff-Pabilonia (2001), who finds, based on US data, that parental allowances decrease employment for teenagers in the age range between 14 and 16 years of age.

On the other hand, the effect of hours worked on parental transfers is negative, but much smaller in size, and insignificant for both boys and girls. This suggests that parents do not adjust their transfer payments to the child's labour supply.

Wage rates have the expected positive direct effect on labour supply. We first discuss the direct structural effect. Evaluated at the average level of transfers and wages, an increase in the wage rate by one pound increases labour supply by about 0.75 hours. The effect on girls' labour supply is considerably larger - an increase by one pound leads to increase supply of labour by about 1.07 hours. This gives wage elasticities at the mean of about 0.56 for boys and 0.78 for girls, well within the broad range of labour supply elasticities found for adults in the labour supply literature.

We report the overall effect on hours worked of an increase in the wage rate in the last row of the table. This effect takes account of the second order effects by decreasing parental transfers: As the increase in labour supply as well as the direct wage effect leads to a reduction in transfers, this leads to a further increase in hours worked. As expected from the small and insignificant estimates of changes in hours on transfer 
Table 5: Hours Worked and Transfers, Girls

\begin{tabular}{|c|c|c|c|c|c|c|c|c|}
\hline & \multicolumn{2}{|c|}{ Hours } & \multicolumn{2}{|c|}{ Hours, Total } & \multicolumn{2}{|c|}{ Transfers } & \multicolumn{2}{|c|}{ Transfers, Total } \\
\hline & Coef. & Std. Err. & Coef. & Std. Err. & Coef. & Std. Err. & Coef. & Std. Err. \\
\hline Intercept & 1.817 & 1.324 & - & - & 6.654 & 0.696 & - & - \\
\hline Father Works & 0.889 & 0.570 & 0.878 & 0.599 & 0.019 & 0.345 & 0.003 & 0.370 \\
\hline Father Farmer & -1.596 & 1.120 & -1.470 & 1.049 & -0.229 & 0.641 & -0.219 & 0.646 \\
\hline Father Self Employed & 0.718 & 0.895 & 0.392 & 0.955 & 1.092 & 0.538 & 1.083 & 0.527 \\
\hline Mother Works & 1.084 & 0.374 & 1.019 & 0.390 & 0.252 & 0.240 & 0.217 & 0.234 \\
\hline East & -0.369 & 0.630 & -0.213 & 0.639 & -0.482 & 0.404 & -0.478 & 0.415 \\
\hline North West & -1.902 & 0.648 & -2.117 & 0.641 & 0.644 & 0.412 & 0.711 & 0.430 \\
\hline North & -3.064 & 0.733 & -3.296 & 0.773 & 0.673 & 0.461 & 0.799 & 0.497 \\
\hline South West & -3.433 & 0.901 & -4.019 & 0.885 & 1.803 & 0.504 & 1.953 & 0.544 \\
\hline Independent School & -3.960 & 0.944 & -4.286 & 0.994 & 0.749 & 0.539 & 0.978 & 0.553 \\
\hline Special ne & -3.463 & 1.381 & -3.239 & 1.445 & -0.690 & 0.647 & -0.588 & 0.686 \\
\hline Mode & 0.549 & 0.403 & 0.610 & 0.399 & -0.244 & 0.245 & -0.253 & 0.247 \\
\hline Technical Scho & -2.096 & 2.130 & -1.505 & 2.418 & -1.521 & 2.752 & -1.549 & 2.915 \\
\hline Gran & -1.464 & 0.565 & -1.451 & 0.580 & -0.183 & 0.382 & -0.074 & 0.400 \\
\hline Age & -0.302 & 0.115 & -0.305 & 0.119 & 0.009 & 0.067 & 0.016 & 0.068 \\
\hline Age Mother l & -0.304 & 0.145 & -0.235 & 0.148 & -0.237 & 0.081 & -0.225 & 0.087 \\
\hline Female & 0.000 & 0.000 & 0.000 & 0.000 & 0.000 & 0.000 & 0.000 & 0.000 \\
\hline N. Older Siblings & -0.337 & 0.141 & -0.349 & 0.149 & 0.031 & 0.070 & 0.052 & 0.076 \\
\hline N. Younger Siblings & 0.040 & 0.137 & 0.192 & 0.130 & -0.486 & 0.078 & -0.488 & 0.078 \\
\hline Ability Test Score Age 11 & 3.866 & 1.049 & 4.393 & 1.079 & -1.266 & 0.626 & -1.496 & 0.634 \\
\hline Household in & 0.000 & 0.000 & -0.167 & 0.060 & 0.538 & 0.085 & 0.537 & 0.088 \\
\hline Adjus & - & - & - & - & 0.725 & 0.013 & - & - \\
\hline $\mathrm{T}$ in $\mathrm{H}$ & -0.312 & 0.105 & - & - & - & - & - & - \\
\hline H in Transfers & - & - & - & - & -0.041 & 0.066 & - & - \\
\hline w in Hours & 1.067 & 0.057 & - & - & - & - & - & - \\
\hline Total Effect Wage rate & - & - & 1.078 & 0.066 & - & - & -0.047 & 0.069 \\
\hline Variance Hours & 7.205 & 0.183 & - & - & - & - & - & - \\
\hline Variance Transfers & - & - & - & - & 4.787 & 0.081 & - & - \\
\hline Log likelihood & & & & & & & & \\
\hline
\end{tabular}


payments, these total labour supply effects are very similar to the direct effects, for both girls and boys.

We report in this row also the wage effects on parental transfer payments. These are the indirect effects working through increasing child's labour supply. The effects are negative for both boys and girls, but small. For boys, an increase in wages by one pound reduces transfer payments by about 6 pence. Effects are not statistically significant.

As we discussed above, some teenagers receive transfers in kind, which we do not observe in our data. However, we have qualitative information on whether children are supposed to use received cash transfers for covering expenses like clothing, travel, etc. We have implemented this information in the model by multiplying transfer thresholds by a correction factor (see section 4). The estimate of the threshold parameter is significantly smaller than one, as expected. It can be interpreted as capturing the difference between the utility of transfers for teenagers who do not ( $60 \%$ of the sample) and do (40\%) have to pay certain expenses from their cash transfers. According to this estimate, a boy who obtains, for example, 10 pounds per week and has to cover other expenses is equally well off as if he had no expenses to cover and received 6.76 pounds per week. For girls, the respective number is slightly larger, at 7.25 pounds per week.

\subsection{Family and Individual Characteristics}

We will now discuss the other coefficient estimates. Columns 1 present results for the labour supply equation. There are some interesting differences in parameter estimates between boys and girls. Most notable is the large and positive effect of fathers being 
self employed or farmers on the labour supply of boys. Teenage boys whose father is a farmer work about 6 hours more than other boys, and boys whose father is self employed work 2.6 hours more, with the total effects being slightly larger. This most likely reflects an early involvement of the child in the parental business or on the parental farm. Both variables have no impact on transfer payments. For girls the effect of these variables on labour supply are insignificant. However, other than for boys, the fact that the father is self employed increases transfer payments by one pound, and this effect is significant.

Another notable difference between boys and girls is the effect of ability test scores on transfer payments and labour supply. While higher test scores decrease significantly labour supply for boys (the variable is scaled between 0 and 1), they have an opposite, and in magnitude larger effect on labour supply of girls. As we discussed above, both effects have an interpretation. One the one hand, high achievers may be more efficient in absorbing academic material, and therefore have more time for other activities, like part time work. The estimates suggest that this is the case for teenage girls. On the other side, those with high test scores may have higher returns from investments into academic education, and spend more time in learning activities. This interpretations seems to be supported by the data for teenage boys.

For both boys and girls, higher test scores are associated with lower transfer payments. Although significant, these effects are very small, and of similar size for both groups.

Parental education is associated with lower labour supply of teenagers. However, while for boys effects are small and not significant, the effects of both mother's and father's education on girls' labour supply are larger, of roughly equal size, and significant. This suggests that better educated parents consider part time work of their daughters 
as less appropriate. They may have greater concern about educational achievements, which they may perceive as being detrimentally affected by part time work. These concerns seem to be less prevalent for sons.

Notable is also the negative relationship between mother's education and transfer payments for both boys and girls, implying that, conditional on family income, better educated mothers seem to consider generous transfer payments as less appropriate.

The effects of the different school types are all relative to comprehensive schools, and generally larger in magnitude for boys. The strongest effect is for attendance of an independent (fee-paying) school, with larger coefficient estimates for boys than for girls. Attendance at an independent school reduces labour supply by nearly 6 hours for boys and 4 hours for girls, with the total effects being even larger. While the direct effect of this school type on transfer payments is non-significant, the total effect is larger and significant, suggesting that the loss in cash money of teenagers at independent schools by working less induces slightly higher transfer payments.

Siblings are likely to affect labour supply of teenagers, with expected different effects of younger and older siblings. While older siblings may provide information about jobs and working experience, and therefore ease teenagers' labour market entry, younger siblings may have the opposite effect, as they may needed to be looked after. Transfer payments may likewise be affected by siblings, as they may reduce available resources. Our estimation results suggest that for boys, the direct effect of the presence of younger siblings on labour supply is positive, while the presence of older siblings is not significant. This is different from what we expected. Furthermore, the total effect of younger siblings is larger than the direct effect, due to younger siblings leading to a significant reduction in transfer payments (as expected), which leads in turn to 
increased supply of labour. For girls, younger siblings have the same effect on transfer payments, but there is no effect on labour supply. On the other hand, older siblings lead to lower supply of labour.

An important variable is parental income. Parental income has a positive direct impact on transfer payments, and the estimate on the log income variable is rather well determined. An additional 100 pounds of weekly household income increases transfer payments by about half a pound, with similar effects for boys and girls.

Our theoretical model implies that parental income should affects labour supply only indirectly, via transfer payments. These indirect effects are precisely estimated, and similar in size for both groups. On average, an increase of weekly income by one hundred pound decreases hours of work by about 0.14 for boys and 0.17 for girls, where this effect works through increased transfer payments. This may seem to be a modest effect; however, it has quite strong implications for labour supply decisions of children who belong to families at the top and bottom percentiles of the income distribution.

Family income is excluded from the labour supply equation - a restriction which follows directly from our theoretical model. We tested for this by estimating the model including income in both labour supply and transfer equations. For both boys and girls, family income is insignificant in the labour supply equation, with a t-value for boys of 1.14 , and for girls of 0.13 . This supports the structure imposed by our model, which suggests that the way family income affects labour supply of teenagers is through transfer payments only.

As discussed above, our model allows us to retrieve the structural parameters from our estimation results. We have estimated these parameters for both groups. The 
estimates of the structural parameters in the labour supply equation were already discussed. Their signs are in line with economic theory and guarantee that the utility function is quasi-concave. The estimates of the parameters of the parents utility function also have the signs that can be expected from theory and satisfy the inequality restriction $0<\gamma_{1}<\gamma_{2}$ that is needed for coherency.

\section{Conclusions}

In this paper, we investigate the labour supply of children still living in the parental household and attending school full time together with the cash transfers they receive from their parents. Descriptive statistics suggest that there is a strong association between parental transfer payments and labour supply of teenagers. They show that the two processes are likely to interact with each other, and appropriate modelling should take this into account. We first develop a simple theoretical model, where children condition their labour supply decision on transfers received, and where parents condition their transfer decisions on the child's labour supply. We use the insights provided by this model to specify an econometric model, which exploits direct observation on parental transfers to their children as well as information on the child's labour supply and the wages teenagers receive. Such data are rarely available, and our analysis is a first attempt at an empirical assessment of the determinants of the different income flows for teenagers still in full time education. In doing so it also contributes to the literature on intra-household allocation, including the interactive nature of this process.

We explicitly allow for the possibility that the teenagers' behaviour feeds back to affect that of the parents in their decision of what transfers to give, and vice versa. Our 
findings suggest that teenagers' labour force participation does indeed reduce parental transfers, but the effect is very small, and not significantly different from zero. On the other side, the effect of transfers on teenagers' labour supply is quite substantial, and precisely estimated. Elasticities are of the magnitude of about -0.6 at the mean - quite large if compared with the range of estimates for adult income elasticities.

A further interesting finding is that teenagers seem to react sensitively to changes in wages, where labour supply elasticities evaluated at the mean are 0.56 for boys and 0.78 for girls. This is in the range found in the labour supply literature for adults.

Our analysis allows us to capture differences in payments due to some teenagers receiving goods in kind which have to be financed out of cash allowances by others. We take account of this by allowing the thresholds of transfer payments to differ between these two groups. Our estimates suggest that teenagers who have to finance items provided to others in kind are equally well of than teenagers that receive about 30 percent lower allowance payments, but do not have to cover certain expenses (like clothes and books).

Overall, our analysis suggests that teenagers react sensitively to parental transfers when making labour supply decisions. As we discussed above, there is a growing literature that investigates the effect of labour supply of teenagers while in full time education on later outcomes. Our results suggests cash allowances as one possibility for parents to take influence on their childrens' labour supply. Our analysis also suggests that parental transfers are not responsive to teenagers' labour supply. In addition, we find substantial heterogeneity in payments of transfers according to family background and school type attended. 
Consumption of teenagers is substantial, and investigation of their consumption choices will almost certainly be subject of intensive future research. Key pre-requisite for consumption of those teenagers still in full time education is availability of financial resources. Our study is a first attempt to shed light on the two key sources of financial means for consumption, and how the processes that describe their acquisition interact within the household. Any work describing teenage consumption choices will have to address issues investigated in this paper. 


\section{References}

- Altonji, J.G., G.F. Hayashi, and L.K. Kotlikoff (1997), "Parental Alruism and Inter Vivos transfers: Theory and Evidence", Journal of Political Economy, 105, 1121-1166.

- Bhalotra, S. And C. Heady (2000), " Child farm labour: Theory and evidence", Discussion Paper 24, LSE Development and Distribution series, July 2000 .

- BAsu, K. (1999), "Child Labour, Cause, Consequence and Cure, with remarks on International Labour Standards", Journal of Economic Literature, 37, 1083-119.

- Becker, G.S. (1974), "A Theory of Social Interaction", Journal of Political Economy, 82, 1063-94.

- Becker, G.S. (1981), "Altruism in the Family and Selfishness in the Market", Economica, 48, 1-15.

- Becker, G.S. (1993), A Treatise on the Family, enlarged edition, Cambridge, Mass.: Harvard University Press.

- Bergstrom, T.C. (1989), "A Fresh Look at the Rotten Kid Theorem-And Other Household Mysteries", Journal of Political Economy, 97, 1138-1159.

- Blundell, R. And MaCurdy(1999), "Labor supply: a review of alternative approaches", in: O. Ashenfelter and D. Card (eds.), Handbook of Labor Economics, Vol. 3A, North-Holland, Amsterdam, 1559-1695.

- Dunn, T.A. And J.W. Phillips (1997), "The Timing and Division of Parental Transfers to Children", Economic Letters, 54, pp.135-137

- Dustmann, C., Micklewright, J., Rajah, N. And S. Smith (1996), "Earnings and Learning: Educational Policy and The Growth of Part-Time Work by Full-time Pupils" Fiscal Studies, 79-103.

- Dustmann, C., N. Rajah and A. van Soest (2003), "Class Size, Education, and Wages", Economic Journal, 113, F100-F120.

- EhrenberG, R.G. And D.R. Sherman (1983), "Employment while in college, academic achievement, and postcollege outcome", Journal of Human Resources, $22,1-23$. 
- Gourieroux, C., J.J. Laffont and A. Monfort (1980), "Coherency conditions in simultaneous linear equation models with endogenously switching regimes", Econometrica, 48(3), 675-698.

- Hausman, J. (1985), "The Econometrics of nonlinear budget sets," Econometrica, 53, 1255-1283.

- Hochguertel, S. And H. Ohlsen (2000), "Compensatory Inter Vivos Gifts", Working Paper No. 319, Annadale-on-Hudson, New York: The Jerome Levy Economic Institute of Bard College.

- Hotz, V.J., L.C. Xu, M. Tienda, A. Ahituv (2002), "Are there Returns to the Wages of young Men from Working while in School?", Review of Economics and Statistics, 84, 221-236.

- Juerges, H. (2000), "Of Rotten Kids and Rawlsian Parents: The Optimal Timing of Intergenerational Transfers" Journal of Population Economics, 13, 147-157.

- Light, A. (2001), "In-School Work Experience and the Return to Schooling", Journal of Labor Economics 19, 65-93.

- Michael R.T. and Tuma N.B. (1984), "Youth Employment: Does Life Begin at 16?", Journal of Labor Economics, 2(4), 464-476.

- Micklewright, J. (1986), "A Note on Household Income data in NCDS3", NCDS User Support Group Working Paper 18, City University.

- Micklewright, J., Rajah, N. And Smith, S. (1994), "Labouring and Learning: Part-Time Work and Full-Time Education", National Institute Review, 148, 73-85.

- Rosenzweig, M.R. And R. Evenson (1977), "Fertility, Schooling, and the Economic Contribution of Children in Rural India: An Econometric Analysis", Econometrica, 45, 1065-1079.

- Ruhm, C. (1997), Is High School Employment Consumption of Investment?, Journal of Labor Economics 14, 735-776.

- Sauer, R.M. (2002), "Educational Financing and Lifetime Earnings", mimeo, Hebrew University Jerusalem.

- Sly, F. (1993), "Economic Activity of 16 and 17 year olds", Employment Gazette, July, 307-12. 
- Van Soest, A., A. Kapteyn and P. Kooreman (1993), "Coherency and Regularity of Demand Systems and Inequality Constraints", Journal of Econometrics, 57, 161-188.

- Wulff Pabilonia, S. (2001), "Evidence on Youth Employment, Earnings and Parental Transfers in the National Longitudinal Survey of Youth 1997", Journal of Human Resources, 36(4), 795-822. 


\section{Appendix}

Table 6: Heckman Selection Model for Log Hourly Wage Rate

\begin{tabular}{|c|c|c|c|c|c|c|c|c|}
\hline & \multicolumn{4}{|c|}{ Boys } & \multicolumn{4}{|c|}{ Girls } \\
\hline & \multicolumn{2}{|c|}{ Wage } & \multicolumn{2}{|c|}{ Selection } & \multicolumn{2}{|c|}{ Wage } & \multicolumn{2}{|c|}{ Selection } \\
\hline & Coef. & Std. Err. & Coef. & Std. Err. & Coef. & Std. Err. & Coef. & Std. Err. \\
\hline Intercept & -1.359 & 0.126 & -0.018 & 0.164 & -1.421 & 0.102 & 0.225 & 0.165 \\
\hline Father Works & 0.017 & 0.064 & 0.215 & 0.090 & -0.003 & 0.054 & 0.123 & 0.091 \\
\hline Father Farmer & -0.155 & 0.107 & 0.506 & 0.175 & -0.069 & 0.107 & -0.203 & 0.171 \\
\hline Father Self Employed & 0.124 & 0.083 & 0.416 & 0.134 & 0.070 & 0.073 & 0.221 & 0.131 \\
\hline Mother Works & 0.182 & 0.041 & 0.217 & 0.058 & 0.063 & 0.035 & 0.178 & 0.058 \\
\hline East & 0.061 & 0.066 & 0.044 & 0.098 & 0.105 & 0.056 & 0.025 & 0.098 \\
\hline North West & -0.121 & 0.068 & -0.164 & 0.099 & -0.075 & 0.058 & -0.338 & 0.098 \\
\hline North & -0.180 & 0.077 & -0.333 & 0.107 & -0.231 & 0.070 & -0.603 & 0.110 \\
\hline South West & -0.134 & 0.092 & -0.089 & 0.133 & -0.126 & 0.089 & -0.695 & 0.133 \\
\hline Grammar School & 0.095 & 0.063 & 0.017 & 0.089 & -0.062 & 0.052 & -0.246 & 0.084 \\
\hline Special needs school & -0.421 & 0.135 & -0.432 & 0.167 & -0.281 & 0.153 & -0.502 & 0.211 \\
\hline Technical School & -0.075 & 0.183 & 0.238 & 0.288 & -0.192 & 0.226 & -0.319 & 0.348 \\
\hline Modern School & 0.049 & 0.042 & 0.132 & 0.061 & -0.017 & 0.037 & 0.036 & 0.063 \\
\hline Independent School & -0.259 & 0.130 & -0.649 & 0.142 & -0.215 & 0.105 & -0.717 & 0.141 \\
\hline N. Older Siblings & 0.009 & 0.013 & 0.009 & 0.019 & -0.005 & 0.013 & -0.052 & 0.020 \\
\hline N. Younger Siblings & 0.013 & 0.014 & 0.062 & 0.020 & 0.038 & 0.013 & 0.045 & 0.020 \\
\hline Ability Test Score Age 11 & -0.300 & 0.105 & -0.182 & 0.146 & -0.141 & 0.100 & 0.618 & 0.160 \\
\hline Family Income & & & -0.022 & 0.015 & & & -0.003 & 0.001 \\
\hline Age Father left School & & & -0.004 & 0.019 & & & -0.031 & 0.015 \\
\hline Age Mother left School & & & -0.002 & 0.001 & & & -0.028 & 0.020 \\
\hline rho & & & 0.668 & 0.075 & & & 0.686 & 0.061 \\
\hline sigma & & & 0.687 & 0.032 & & & 0.599 & 0.025 \\
\hline Log likelihood & \multicolumn{4}{|c|}{-2879.63} & \multicolumn{4}{|c|}{-2545.13} \\
\hline N. Obs. & \multicolumn{4}{|c|}{2563} & \multicolumn{4}{|c|}{2472} \\
\hline N. Working & \multicolumn{4}{|c|}{1326} & \multicolumn{4}{|c|}{1254} \\
\hline
\end{tabular}

Wage equations. Participation equation is identified by excluding parental education and family income; these variables are jointly significant in the participation equation. The correlation between the unobservables in participation- and wage equation is given by Rho. 